\title{
As informações de custos no suporte às atividades de marketing de serviços: Uma vantagem competitiva no setor hoteleiro
}

Ivonaldo Brandani Gusmão

E-mail: ivonaldo@unicentro.br

\author{
Valdir Michels \\ E-mail: valdirmichels@yahoo.com.br
}

Carlos Alberto Kühl

E-mail: ckuhl@unicentro.br

\begin{abstract}
RESUMO
O objetivo deste artigo é analisar as relações entre marketing no setor hoteleiro e a utilização das informações de custos para fins estratégicos nesse segmento, e o suporte que pode ser evidenciado nas atividades de serviços em sua demanda específica no setor de hotelaria, pois, para desenvolver o seu produto ou serviço, precisa atribuir-lhe preço, distribuí-lo ao mercado de consumidores e estimular a demanda de mercado, reconhecendo a importância destas estratégias para 0 desenvolvimento de seu negócio. Dada a importância do setor de serviços de hotelaria na economia brasileira, mister se faz identificar as estratégias adotadas pelos gestores das empresas desse segmento para se manterem competitivas no mercado. A pesquisa se justifica, ainda, pela carência de trabalhos específicos sobre o uso estratégico das informações de custos no processo de gestão estratégica de marketing em hotelaria. Frente a este quadro, este estudo teve como propósito verificar empiricamente se os gestores de empreendimentos hoteleiros de Curitiba e da região metropolitana aplicam os conceitos de marketing de serviços para desenvolver estratégias gerenciais voltadas à tomada de decisão. Verificou-se, no que diz respeito ao posicionamento estratégico dos hotéis de médio e grande porte, que predomina a estratégia de diferenciação para as atividades-fim como um todo. Quanto ao provimento de informações de custos estratégicos, os dados revelam que os gestores dos hotéis pesquisados recebem mais informações de custos operacionais do que informações de custos relativos aos elos da cadeia de valor e ao mercado, focos de uma gestão estratégica.
\end{abstract}

Palavras-chave: Marketing de custos. Custos de Serviços. Setor Hoteleiro. 
As informações de custos no suporte às atividades de marketing de serviços: Uma vantagem competitiva no setor hoteleiro Ivonaldo Brandani Gusmão, Valdir Michels, Carlos Alberto Kühl

\begin{abstract}
The objective of this article is to know the relationships among marketing in the hotel section and the use of the information of costs for strategic in that segment and the support that it can be evidenced in the activities of services in her specific demand in the hostelry section, because, to develop his product or service, he needs to attribute price, to distribute it to the consumers' market and to stimulate the market demand, recognizing the importance of these strategies for the development of his business. The importance of the section of hostelry services is verified in the Brazilian economy and this article looks for to identify which the strategies are adopted by the managers for the companies of that segment for us to maintain her competitive. The research is justified, still, for the lack of specific works on the strategic use of the information of costs in the process of strategic administration of marketing in hostelry. Front to this picture, this study had as purpose to verify empirically if the managers of hotel enterprises of Curitiba and of the metropolitan area they apply the concepts of marketing of services to develop returned managerial strategies the activities of socket of decision. It was verified that says respect to the strategic positioning of the hotels of medium and big load in what, that the differentiation strategy prevails for the activities as a completely. As for the provision of information of strategic costs, the data revealed that the researched hotel managers receive more information of operational costs than information of relative costs to the links of the chain of value and the market, focuses of a strategic administration.
\end{abstract}

Word-key: Marketing costs. Costs in the services. Hotel section.

\title{
1 INTRODUÇÃO
}

Este estudo tem como objetivo conhecer as relações de marketing no setor hoteleiro e verificar se os gestores dos hotéis utilizam informações de custos para dar suporte à gestão estratégica de marketing, procurando investigar aspectos relativos a essa prática, com o propósito de constatar a aplicação da teoria no setor e avaliar as relações entre a utilização dos custos na prestação de serviços e o suporte que pode ser evidenciado nas atividades de marketing, assim como a sua demanda específica no setor de hotelaria, como informação para a tomada de decisão.

De modo geral os gestores empresariais vêm se valendo de instrumentos 
As informações de custos no suporte às atividades de marketing de serviços: Uma vantagem competitiva no setor hoteleiro Ivonaldo Brandani Gusmão, Valdir Michels, Carlos Alberto Kühl

gerenciais capazes de prover informações gerenciais estratégicas, capazes de criar e desenvolver vantagem competitiva sustentável. Uma das formas de garantir a continuidade operacional e o fortalecimento do posicionamento da empresa no mercado, é a aplicação de técnicas de contabilidade gerencial como informação estratégica aliada ao marketing de serviços.

A contabilidade gerencial preconiza a utilização de informações de custos para apoio ao processo de gestão estratégica. Neste aspecto, torna-se indispensável que a contabilidade forneça ou coloque à disposição do gestor informações de custos, de relevância estratégica, e que possam dar suporte às decisões tomadas na empresa, permitindo uma vantagem competitiva em relação aos competidores.

A realização deste estudo justifica-se pela carência de trabalhos específicos sobre o uso estratégico das informações de custos no processo de gestão estratégica de marketing das empresas do setor hoteleiro, apresentando tanto relevância teórica quanto prática. Do ponto de vista teórico, busca consolidar a literatura desenvolvida na área de contabilidade gerencial e de marketing de serviços. Na perspectiva prática, busca verificar a aplicação das técnicas da contabilidade gerencial como ferramenta essencial para a obtenção de vantagem competitiva voltada ao marketing de serviços.

A escolha do setor hoteleiro é justificada pela relevância que este tem na economia brasileira, refletida tanto pela sua participação ativa no Produto Interno Bruto (PIB), quanto no seu potencial de gerar emprego e captação de recursos internacionais por meio de turistas.

No desenvolvimento desse artigo, apresenta-se uma revisão da literatura e os fundamentos teóricos, abordando a gestão estratégica, a gestão de custos em empresas de serviços de hotelaria e competitividade do setor como, também, os resultados de uma pesquisa empírica realizada junto aos gestores dos hotéis que compõem a amostra.

Este artigo está organizado em seis seções incluindo esta introdução, a 
As informações de custos no suporte às atividades de marketing de serviços: Uma vantagem competitiva no setor hoteleiro Ivonaldo Brandani Gusmão, Valdir Michels, Carlos Alberto Kühl

caracterização do problema da pesquisa, a fundamentação teórica, a metodologia da pesquisa, a análise dos resultados obtidos e as considerações finais.

\section{PROBLEMA DE PESQUISA}

A utilização estratégica de informações de custos no processo da gestão estratégica é uma das formas de inovar e enfrentar a competição, e os métodos gerenciais de gestão de custos podem criar vantagem competitiva nas empresas, auxiliando-as a vencer nos mercados altamente competitivos de hoje. Diante desse quadro surgiu o seguinte questionamento: os gestores dos hotéis utilizam informações de custos para desenvolver e implementar estratégias gerenciais que podem ser aliadas ao marketing de serviços? Os sistemas de contabilidade de custos e gerencial desenvolvidos estão fornecendo informações para os gestores administrarem suas empresas e competirem no mundo atual dos negócios?

\section{FUNDAMENTAÇÃO TEÓRICA}

\subsection{Marketing de Serviços Aplicado em Hotelaria}

Com a economia globalizada, o setor de turismo necessita vislumbrar novas soluções que possam atender aos anseios, desejos e fantasias de seus clientes, com uma equipe de profissionais que saibam identificá-los corretamente. Os profissionais de marketing das empresas prestadoras de serviços devem estar aptos a reconhecer que o mercado ao se globalizar passa a exigir conhecimentos que levem a formular estratégias consistentes para evitar problemas financeiros.

Mas o que é um serviço, como defini-lo e como diferenciar serviço ou produto? Pode-se definir serviço como algo essencialmente intangível, que não resulta em propriedade. O serviço pode ou não estar ligado a um produto físico. Assim, os serviços são desempenhos no tempo e espaço que geram valor para o cliente. 
As informações de custos no suporte às atividades de marketing de serviços: Uma vantagem competitiva no setor hoteleiro Ivonaldo Brandani Gusmão, Valdir Michels, Carlos Alberto Kühl

O setor de serviços é muito importante para o país, pois dele segmentam-se vários setores, tais como hotelaria, objeto dessa pesquisa, companhias aéreas, locação de veículos, lavanderias e agências de viagens. Segundo dados do Banco Central do Brasil (2007), o setor de serviços representou aproximadamente $53 \%$ do PIB nacional, e dentro de serviços o volume de negócios gerados pelo turismo é muito significativo.

Dados da Empresa Brasileira de Turismo - EMBRATUR (2007, p. 2) revelam que pelo quinto ano consecutivo observa-se a expansão de divisas no país por meio do turismo internacional. Dados do Banco Central do Brasil (2007) revelam recorde histórico dos gastos de turistas estrangeiros em visita ao Brasil. Em 2006 foram US\$ 4,3 bilhões, $11,78 \%$ a mais do que os US $\$ 3,9$ bilhões auferidos em 2005 , até então a melhor marca da série iniciada em 1969. A receita obtida em 2006 é 116,02\% maior do que a de 2002 (US\$ 2 bilhões), o primeiro ano dessa sequência positiva, seguindo-se US\$ 2,5 bilhões em 2003 e US \$ 3,2 bilhões em 2004. Os resultados alcançados em 2006 representam uma conquista, principalmente considerando alguns problemas em virtude da valorização do câmbio, dos problemas enfrentados nos aeroportos e da crise financeira e operacional de companhias aéreas como a VARIG, que foi responsável pela não vinda de cerca de 400 mil turistas estrangeiros ao país.

A hotelaria é um dos principais ramos do turismo, já que atende à função básica do viajante que é viabilizar sua permanência na cidade visitada, e é um setor promissor no Brasil, visto que a demanda turística e o setor vêm se estruturando, com excelentes possibilidades de expansão.

Para a EMBRATUR (2007, p. 10), o motivo da estadia e segmentação do mercado do percentual de turistas que se hospedaram, no último trimestre de 2006, por motivo de negócios/trabalho, totalizou 48\%; a lazer/passeio, 31\%; para a participação em congressos/feiras, $14 \%$; e por outras razões, $7 \%$. Diante do exposto, as empresas de hotelaria têm voltado seu foco para o turismo de negócios, como pode ser observado na Figura 1. 
As informações de custos no suporte às atividades de marketing de serviços: Uma vantagem competitiva no setor hoteleiro Ivonaldo Brandani Gusmão, Valdir Michels, Carlos Alberto Kühl

No que tange à segmentação do mercado, a fatia correspondente a hóspedes brasileiros, em Out/Dez/2006 foi de $72 \%$, e a de estrangeiros $28 \%$, contra, respectivamente, $76 \%$ e $24 \%$ em igual período de 2005.

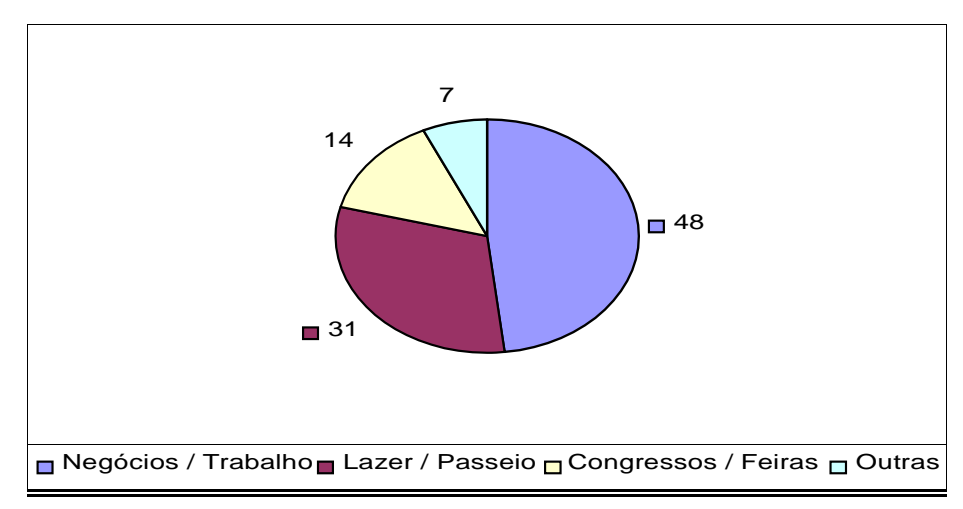

Figura 1 - Segmentação do mercado por motivo de hospedagem (\%)

Em vista do que foi até aqui exposto, os hotéis brasileiros vão precisar focar seu negócio com muita qualidade em seus serviços e muita criatividade em seu marketing, para ter competitividade perante as grandes redes nacionais e internacionais, visando sua sobrevivência num mercado tão volátil e de natureza intangível, e avaliar como os seus controles gerenciais podem auxiliar na tomada de decisão.

\subsection{Os 4 P's: Produto, Ponto, Preço, Promoção no setor de Hotelaria}

Para Kotler (1998, p. 30), marketing é um processo social por meio do qual as pessoas obtêm aquilo de que necessitam e o que desejam com a criação, oferta e livre negociação de produtos ou serviços.

Na visão da American Marketing Association - AMA (2007, p. 7), marketing é o processo de planejamento e execução que compreende concepção, apreçamento, promoção e distribuição de ideias, ercadorias e serviços, para criar trocas que 
As informações de custos no suporte às atividades de marketing de serviços: Uma vantagem competitiva no setor hoteleiro Ivonaldo Brandani Gusmão, Valdir Michels, Carlos Alberto Kühl

satisfaçam os objetivos individuais e organizacionais.

No setor de negócios turísticos, ter um bom produto é o primeiro e mais importante passo para atender as expectativas dos consumidores. Mas isto não basta, é preciso ter pontos para levar esses serviços atraentes até o cliente, e trabalhar bem a distribuição por meio de lojas, agentes de viagem, internet, representantes autônomos e outros meios para disponibilizar o serviço ou produto, até o consumidor ou usuário final.

Para Cobra (2001, p. 46-47), por meio da promoção de vendas é preciso divulgar e promover o serviço que se quer vender seja ele um hotel, uma excursão, uma viagem de negócios ou mesmo um evento. E, por fim, o preço é o fator chave de decisão de compra e para isso o vendedor deve saber confrontar o preço, utilizando essa arma para valorizar o produto ofertado ou mesmo para estimular a compra.

\subsubsection{Hotel: Produto ou Serviço?}

Para Kotler (1998, p. 412), serviço é definido como "qualquer ato ou desempenho que uma parte possa oferecer a outra, que seja essencialmente intangível e não resulte na propriedade de nada". Levitt (1990, p.105) argumenta que para se entender a diferença entre produto e serviço, deve-se "mudar as palavras para tangíveis e intangíveis".

Os produtos tangíveis podem ser diretamente experimentados, isto é, vistos, tocados, degustados e testados, e os produtos intangíveis raramente podem ser experimentados ou testados antecipadamente. Portanto, se a fonte do benefício essencial é mais tangível do que intangível, ele é considerado um produto, se esse benefício é mais intangível do que tangível, ele é considerado um serviço.

O hotel deve ser considerado uma rede de serviços e produtos? Para responder esse questionamento, é preciso entender-se que um hotel deve oferecer desde acomodações em apartamentos, até vendas de produtos, como: comidas e bebidas em 
As informações de custos no suporte às atividades de marketing de serviços: Uma vantagem competitiva no setor hoteleiro Ivonaldo Brandani Gusmão, Valdir Michels, Carlos Alberto Kühl

seus restaurantes e apartamentos, bares, boates e áreas de eventos. Alguns hotéis oferecem, ainda: sauna, sala de ginástica, cabeleireiro, business center e serviços de recepção diferenciados. Portanto, devem oferecer uma estrutura adequada aos desejos e anseios de seus clientes, com serviços que os encantem e possam atraí-los e, se possível, fidelizá-los.

Um novo produto em turismo é uma forma de revigorar negócios e estimular o consumo. "O sucesso de um hotel é o mesmo de uma operadora de turismo, ou seja, a inovação com novos e atraentes produtos. " (Cobra, 2001, p. 90).

O marketing no setor de hotelaria deve ser encarado com muito profissionalismo, para que o mercado possa ser atendido em suas expectativas e satisfazer seus consumidores, mediante um cuidadoso equilíbrio dos elementos do composto de marketing: produto, preço, distribuição e promoção, que representam subconjuntos da estratégia geral de marketing.

A partir dessas afirmações, percebe-se que a qualidade do serviço é a base do marketing de serviços, pois o produto é o desempenho do serviço oferecido pela empresa que consolida a competitividade, atraindo a confiança do cliente, o que proporciona um reforço da marca, publicidade, vendas e preços.

\subsection{Estratégia e Gestão Estratégica}

O conceito de estratégia empresarial ganhou destaque com a publicação de Strategy and Structure, de Chandler (1962), Corporate Strategy, de Ansoff (1965), e Estratégias Competitivas, de Porter (1980), autores que contribuíram para a evolução do pensamento estratégico.

De acordo com Ansoff (1977), o conceito de estratégia é relativamente novo na literatura de administração e a sua gênese pode ser situada na arte militar, onde é um conceito amplo, vagamente definido, de uma campanha militar para a aplicação de forças em grande escala contra um inimigo.

Para Chandler (1962, p. 18), estratégia é a determinação dos objetivos básicos 
As informações de custos no suporte às atividades de marketing de serviços: Uma vantagem competitiva no setor hoteleiro Ivonaldo Brandani Gusmão, Valdir Michels, Carlos Alberto Kühl

de longo prazo de uma empresa e a adoção das ações adequadas e aplicação de recursos para atingir esses objetivos.

Porter (1989, p. 22) entende que estratégias competitivas são ações ofensivas ou defensivas para criar uma posição defensável numa indústria, para enfrentar com sucesso as forças competitivas e assim obter um retorno maior sobre o investimento.

Todas essas definições de estratégia se assentam na inseparabilidade entre a organização e o seu entorno que, se por um lado representa uma condicionante à sua atividade, por outro the oferece oportunidades que devem ser aproveitadas. É esta relação entre organização e entorno que dá sentido ao conceito de estratégia.

No mundo dos negócios, a volatilidade e a crescente incerteza têm imposto às empresas considerarem a estratégia como meio de sobrevivência, forçando-as a cada vez mais acompanhar algumas variáveis determinantes para a sua continuidade operacional.

A gestão estratégica deve ser entendida como parte da gestão global das organizações, que se preocupa em acompanhar as ações das entidades em seu ambiente próximo, tais como: concorrentes, fornecedores, clientes e consumidores, além de conceber e implementar estratégias que lhes permitam manter-se à frente dos competidores. Portanto, trata-se de uma gestão cujo objetivo maior é desenvolver valores corporativos, capacidades gerenciais, responsabilidades organizacionais e sistemas administrativos que vinculem tomadas de decisão estratégicas e operacionais, a todos os níveis hierárquicos.

O desenvolvimento promissor do setor turístico tem despertado os gestores desta área sobre a importância da estratégia. O estudo da estratégia e sua relação com a atividade turística é um direcionamento cada vez mais necessário, em face do desenvolvimento que se projeta e espera, bem como dos crescentes e complexos desafios. Esse contexto é marcado pela ideia maior da competição, entendido como indispensável para motivar e impulsionar o sistema em seus propósitos de crescimento 
As informações de custos no suporte às atividades de marketing de serviços: Uma vantagem competitiva no setor hoteleiro Ivonaldo Brandani Gusmão, Valdir Michels, Carlos Alberto Kühl

contínuo. O espírito competitivo, até os dias atuais, continua predominante e constitui a principal força inspiradora justificadora das estratégias das organizações.

Para competir no mundo atual dos negócios, Porter (1991, p. 53), propôs três tipos de estratégia genérica que podem proporcionar às empresas vantagem competitiva sustentável: diferenciação, liderança no custo total e enfoque.

O objetivo de uma estratégia de liderança em custos é oferecer um valor melhor ou igual aos clientes a um custo menor do que aquele oferecido pelos competidores. Uma estratégia de diferenciação busca aumentar o valor ao cliente ao aumentar o que recebe (realização do cliente), portanto, uma vantagem competitiva é criada ao oferecer algo para o cliente que não é oferecido pelos competidores. Uma estratégia de focalização envolve selecionar ou enfatizar, um conjunto de clientes ou segmento de mercado, no qual competir, uma possibilidade é selecionar os mercados e clientes que parecem mais atraentes do que outros.

Para Kim e Oh (2004, p. 67), ao adicionar valor aos clientes, empregados e proprietários tornam-se o tema central da gestão estratégica, na indústria da hospitalidade, o que acaba criando uma vantagem competitiva sustentável.

De fato, por trás da geração de valor está uma gestão eficaz e eficiente dos custos que se alinha aos propósitos estratégicos da empresa, portanto, a consideração de aspectos estratégicos no processo da gestão empresarial é de grande ênfase para uma boa condução do negócio, pois, o planejamento estratégico tornou-se um instrumento essencial em empresas hoteleiras em virtude das peculiaridades do segmento que exige planificação da demanda, oferta e tecnologia, e o sucesso da estratégia é função do preenchimento de determinados requisitos gerenciais considerados críticos para o seu sucesso.

Ansoff (1991, p. 26) sustenta que "[...] a estratégia impõe exigências operacionais: decisões sobre preços e custos, programação da produção para atender a demanda, respostas a mudanças de necessidades de clientes e características tecnológicas e de processos". Por isso, os gestores devem proporcionar ferramentas 
As informações de custos no suporte às atividades de marketing de serviços: Uma vantagem competitiva no setor hoteleiro Ivonaldo Brandani Gusmão, Valdir Michels, Carlos Alberto Kühl

que ajudam a atender essas exigências.

Desta forma, a informação de custos gerada sob o enfoque estratégico, aumenta as chances de um bom desempenho do sistema de gestão estratégica da empresa, e o impacto positivo da informação contábil gerencial no sistema de gestão estratégica se traduz pelo ajustamento da empresa com o ambiente externo, ou seja, um bom posicionamento no mercado.

\subsection{Gestão de Custos em Empresas de Serviços}

Historicamente, as técnicas e práticas de contabilidade de custos têm sido desenvolvidas no setor industrial e, atualmente, a literatura desta área de conhecimento enfatiza a incorporação, cada vez maior, da gestão de custos no processo gerencial das empresas que atuam no setor terciário.

Martins (2001, p. 22) afirma que com "[...] o advento da nova forma de se usar contabilidade de custos, ocorreu maior aproveitamento em outros campos que não o industrial. "No caso de instituição não tipicamente daquela natureza, tais como instituições financeiras, empresas comerciais, firmas de prestação de serviços, etc., onde seu uso para efeito de Balanço era quase irrelevante pela ausência de estoques, passou-se a explorar seu potencial para o controle e até para as tomadas de decisões.

Os gerentes de empresas de serviços ignoraram as informações de custo quando na tomada de decisões, baseando-se apenas em informações financeiras para orçar e controlar dispêndios em seus departamentos funcionais (Atkinson et al., 2000).

A gestão de custos deve estar voltada para a geração de informações gerenciais indispensáveis para tomada de decisões, e o cenário do setor de serviços caracterizado, principalmente, pela acirrada competição e pela incerteza, exige do gestor inovação no gerenciamento dos custos.

$\mathrm{Na}$ hotelaria, a relevância da gestão de custos pode ser verificada quando, ao dispor de um sistema de custos eficaz, o hotel agrega ao seu processo decisório uma informação muito significativa para o seu gerenciamento e avaliação de suas 
As informações de custos no suporte às atividades de marketing de serviços: Uma vantagem competitiva no setor hoteleiro Ivonaldo Brandani Gusmão, Valdir Michels, Carlos Alberto Kühl

estratégias organizacionais, permitindo a identificação e análise das variações ocorridas na alocação de seus recursos, demonstrando as verdadeiras causas dos desvios e realimentando o processo de planejamento, execução e controle, adequando-se, assim, às necessidades informacionais imprescindíveis à sobrevivência e continuidade do negócio.

Para Atkinson et al., (2000, p. 50, por ter "[...] operado muito tempo em mercados favoráveis e sem competição, a maioria das empresas de serviços não tem dado muita importância à mensuração do custo das suas operações. "

Percebe-se que o ambiente onde atuavam as empresas tem representado um fator que propiciou a falta de preocupação com a administração dos custos por parte dos gestores e, diante de um mercado em que não existia uma pressão competitiva, os gerentes das empresas de serviços encontravam-se livres para reduzir custos; melhorar a qualidade e eficiência das operações; introduzir novos produtos que geram lucros; ou eliminar produtos e serviços que incorriam em prejuízos (Atkinson et al, 2000).

Nas decisões empresariais, cada alternativa tem determinados custos e vantagens que precisam ser comparados com os das demais alternativas oferecidas. Um dos conceitos mais importantes da tomada de decisões é representado pelos custos relevantes, que são custos que vão ser incorridos no futuro e apresentarão diferenças nas linhas de ação alternativas. Enfatiza-se o futuro porque as decisões lidam com o que vai acontecer. O que já aconteceu não pode ser alterado (Horngren et.al, 2000).

Hansen e Mowen (1992, p. 459) destacam que ao se escolher entre duas alternativas, só os custos relevantes deveriam ser considerados para a decisão. Custos relevantes são custos futuros que diferem pelas alternativas. Todas as decisões se relacionam ao futuro e, adequadamente, somente custos futuros podem ser relevantes para as decisões. No processo de gestão empresarial a análise de custos deve estar baseada nas decisões tomadas e seus impactos futuros. 
As informações de custos no suporte às atividades de marketing de serviços: Uma vantagem competitiva no setor hoteleiro Ivonaldo Brandani Gusmão, Valdir Michels, Carlos Alberto Kühl

Dentro da perspectiva da relevância dos custos na tomada de decisões gerenciais, Maher (2001, p. 467) traz a análise diferencial de custos como uma valiosa ferramenta gerencial, definindo-a como o processo de estimar receitas e custos de cursos de ação alternativos, e de comparar essas estimativas com o status quo.

Com o aumento da pressão competitiva, os gerentes das empresas de serviços requerem informações precisas e relevantes sobre seus custos efetivos para implementar estratégias gerenciais, fortalecer o posicionamento das empresas no mercado, enfim, criar vantagem competitiva sustentável. Portanto, torna-se indispensável que os gestores administrem custos levando em conta a competitividade do setor, adotando uma visão menos tradicional da gestão de custos, e tendo como desafio a mudança do paradigma da contabilidade gerencial tradicional para a contabilidade gerencial estratégica.

\section{METODOLOGIA DA PESQUISA}

Para alcançar o objetivo proposto, esta pesquisa considera a seguinte classificação: quanto ao objetivo, trata-se de pesquisa exploratória; quanto ao processo da pesquisa: quantitativa e qualitativa; e quanto ao resultado da pesquisa: aplicada.

Esta pesquisa ainda caracteriza-se, quanto aos fins, como sendo uma pesquisa de natureza descritiva, pois, conforme aponta Vergara (2000, p. 47), "[...] busca expor características de determinada população ou de determinado fenômeno", estabelecendo correlações entre variáveis e definindo sua natureza.

Quanto aos meios de investigação, caracteriza-se como sendo uma pesquisa de campo. Trata-se de uma investigação empírica realizada no local onde ocorre ou ocorreu um fenômeno ou que dispõe de elementos para explicá-lo (Vergara, 2000, p. 47).

Para atingir os objetivos estabelecidos, foi realizada uma pesquisa de campo 
As informações de custos no suporte às atividades de marketing de serviços: Uma vantagem competitiva no setor hoteleiro Ivonaldo Brandani Gusmão, Valdir Michels, Carlos Alberto Kühl

para avaliar enunciados descritivos sobre a população. A pesquisa realizada no segundo semestre de 2007, entre os meses de agosto e setembro, consistiu nas seguintes etapas: elaboração de instrumento de pesquisa; pré-teste, alterações no instrumento de pesquisa; escolha da população e amostra; coleta de dados e análise das respostas.

Quanto ao envio do questionário, primeiramente, foram levantados os nomes de todos os hotéis de Curitiba e região metropolitana, por meio de pesquisa junto a Secretaria de Turismo do Estado do Paraná, buscando não somente verificar a quantidade de empresas do ramo hoteleiro, mas seus respectivos e-mails e endereços para contato. Após esta primeira etapa foi enviada por meio eletrônico uma mensagem aos hotéis, explicando o objetivo da pesquisa e verificando a possibilidade de enviar o questionário para obtenção de respostas dos gestores.

O universo da pesquisa compreendeu os 101 empreendimentos hoteleiros de grande, intermediário, médio e pequeno porte, localizados em Curitiba e região metropolitana, de acordo com os critérios de classificação da EMBRATUR.

A amostra do estudo foi composta pelas empresas que se dispuseram a participar da pesquisa, ajustada ao número de respostas consideradas para a análise, como consta na Tabela 1.

Tabela 1 - Amostra ajustada da pesquisa

\begin{tabular}{|l|r|r|}
\hline \multicolumn{1}{|c|}{ Descrição } & \multicolumn{2}{c|}{ Empresas } \\
\cline { 2 - 3 } & \multicolumn{1}{c|}{ Qtde } & \multicolumn{1}{c|}{$\%$} \\
\hline Total de hotéis selecionados para contato & $\mathbf{1 0 1}$ & $\mathbf{1 0 0}$ \\
\hline Hotéis que tem página na Internet, mas não tem e-mail & 11 & 10,89 \\
\hline Hotéis com razão social diferentes, mas com mesmo e-mail & 4 & 3,96 \\
\hline Hotéis que não receberam a pesquisa por estarem com e-mail desatualizado & 24 & 21,78 \\
\hline $\begin{array}{l}\text { Hotéis que alegaram política de não responder a pesquisa, e que não atenderam aos } \\
\text { telefonemas ee-mails. }\end{array}$ & 9 & 8,91 \\
\hline Amostra Ajustada (Hotéis que aceitaram participar da pesquisa) & $\mathbf{5 3}$ & $\mathbf{1 0 0}$ \\
\hline Respostas não recebidas & 13 & 24,53 \\
\hline Respostas desclassificadas & 1 & 1,89 \\
\hline Total de Respostas Ajustada & $\mathbf{3 9}$ & $\mathbf{7 3 , 5 8}$ \\
\hline
\end{tabular}


As informações de custos no suporte às atividades de marketing de serviços: Uma vantagem competitiva no setor hoteleiro Ivonaldo Brandani Gusmão, Valdir Michels, Carlos Alberto Kühl

A desclassificação das respostas recebidas, conforme apresentado na Tabela 1, se deu em razão dos questionários terem retornado incompletos, principalmente as questões que permitiriam responder o objetivo do estudo, impossibilitando, assim, seu aproveitamento.

Todos os hotéis participantes da pesquisa têm página na Internet, sendo que 10,89\% não têm e-mail para contato, e 3,96\% são hotéis que apresentam razão social diferente, mas com o mesmo e-mail. Dos hotéis que tem e-mail, $21,78 \%$ não receberam a pesquisa devido ao fato de não manterem atualizados seus e-mails, e $8,91 \%$ dos hotéis alegaram política de não responder pesquisas ou não atenderam aos e-mails enviados.

De posse dessas informações ajustou-se a amostra para 53 hotéis que aceitaram participar da pesquisa. Foi encaminhado, por e-mail, o arquivo com a pesquisa e foram obtidos 39 questionários respondidos, o que corresponde a uma taxa de $73,58 \%$ dos hotéis que aceitaram participar do estudo, constituindo-se, desta forma, em uma amostra não probabilística, por acessibilidade.

$\mathrm{Na}$ Tabela 2 são apresentadas as classificações dos questionários respondidos por porte de hotel.

Tabela 2 - Porte do hotel em unidades habitacionais

\begin{tabular}{llcc}
\hline & Porte do hotel em unidades habitacionais & \multicolumn{2}{c}{ Número de respondentes } \\
\hline Porte & Número de Unidades Habitacionais (UH) & n & $\%$ \\
\hline Grande & Acima de 100 UH & 5 & 12,82 \\
Intermediário & De 71 a 99 UH & 11 & 28,21 \\
Médio & De 41 a 70 UH & 13 & 33,33 \\
Pequeno & Até 40 UH & 10 & 25,64 \\
\hline \multicolumn{2}{c}{ Total } & $\mathbf{3 9}$ & $\mathbf{1 0 0}$ \\
\hline
\end{tabular}

Os dados coletados na pesquisa de campo foram tratados de forma quantitativa e qualitativa. Quanto à primeira forma, recorreu-se à estatística descritiva e sua análise 
As informações de custos no suporte às atividades de marketing de serviços: Uma vantagem competitiva no setor hoteleiro Ivonaldo Brandani Gusmão, Valdir Michels, Carlos Alberto Kühl

foi realizada mediante tabulação dos dados no SPSS - Statistical Package for the Social Sciences versão 13.

O questionário foi dividido em 6 partes, sendo: Parte 1 - Caracterização do empreendimento hoteleiro e do respondente; Parte 2 - Posicionamento Estratégico; Parte 3 - Uso da informação de custos para fins estratégicos; Parte 4 - Fluxo de informações que alimentam a tomada de decisões estratégicas; Parte 5 - Fluxo de informações sobre marketing; e Parte 6 - Relação à divulgação de sua empresa e seus produtos.

O questionário foi dirigido ao diretor administrativo-financeiro ou função equivalente, visando direcioná-lo ao responsável pelo fornecimento de informações à administração. Para verificação sobre a clareza e precisão das questões e também das alternativas fixas de resposta, o questionário foi previamente submetido a um pré-teste, com dois diretores e dois gerentes, cujas sugestões de melhorias foram incorporadas ao instrumento.

\section{ANÁLISE DOS RESULTADOS}

\subsection{Caracterização do Empreendimento Hoteleiro e do Respondente}

Nesta parte são apresentados os resultados referentes à caracterização do respondente no que se refere ao cargo, ao grau de instrução, ao tempo de atuação no mercado e à categoria do estabelecimento. Tais informações podem ajudar a compreender o fenômeno em estudo, isto é, verificar se os dados referentes ao gestor e ao hotel exercem alguma influência na utilização de informações de custos estratégicos pelos gestores hoteleiros.

Conforme revela a Tabela 3, a maior parte dos gestores entrevistados ocupa cargos de gerência geral $(56,41 \%)$. Na condição de sócio tem-se $28,21 \%$, como proprietário $7,69 \%$, como assistente de gerência $5,13 \%$, e na função desempenhada por familiares $2,56 \%$. 
As informações de custos no suporte às atividades de marketing de serviços: Uma vantagem competitiva no setor hoteleiro Ivonaldo Brandani Gusmão, Valdir Michels, Carlos Alberto Kühl

Tabela 3 - Cargo ou função do respondente na empresa

\begin{tabular}{lcc}
\hline & \multicolumn{2}{c}{ Número de respondentes } \\
\cline { 2 - 3 } Cargo ou função na empresa & $\mathbf{n}$ & $\%$ \\
\hline Proprietário & 3 & 7,69 \\
Sócio & 11 & 28,21 \\
Gerente & 22 & 56,41 \\
Assistente Gerência & 2 & 5,13 \\
Familiar & 1 & 2,56 \\
\hline Total & $\mathbf{3 9}$ & $\mathbf{1 0 0}$ \\
\hline
\end{tabular}

Com relação ao tempo de atuação do gestor no mercado, a Tabela 4 revela que a frequência maior encontra-se no intervalo de 5 a 10 anos, correspondendo a 35,90\%. Segue-se o intervalo de 0 a 5 anos e de 10 a 15 anos, ambos, apresentando uma frequência de 23,08\%, mostrando uma participação considerável dos gestores menos experientes no mercado na amostra pesquisada. Os gestores que se encontram na faixa de 15 a 20 anos equivalem a 12,82\%, enquanto os que atuam há mais de 20 anos correspondem a 5,13\%, representando a menor frequência.

Tabela 4 - Tempo de atuação do respondente no mercado de hotelaria

\begin{tabular}{lcc}
\hline & \multicolumn{2}{c}{ Número de respondentes } \\
\cline { 2 - 3 } Tempo de atuação no mercado & $\mathbf{n}$ & $\%$ \\
\hline De 0 a 5 anos & 9 & 23,08 \\
De 5 a 10 anos & 14 & 35,90 \\
De 10 a 15 anos & 9 & 23,08 \\
De 15 a 20 anos & 5 & 12,82 \\
Acima de 20 anos & 2 & 5,13 \\
\hline Total & $\mathbf{3 9}$ & $\mathbf{1 0 0}$ \\
\hline
\end{tabular}

Quanto ao grau de instrução dos gestores entrevistados, a Tabela 5 indica que os formados no ensino médio representam 7,69\%, enquanto os que possuem grau superior incompleto representam 2,56\%. Gestores com curso superior completo representam 30,77\%, e 58,97\% possuem curso de especialização Lato Sensu. Os dados revelam, portanto, que 10,25\% não possuem formação superior completa, enquanto $89,74 \%$ possuem curso superior completo, o que pode ser um indício de que 
As informações de custos no suporte às atividades de marketing de serviços: Uma vantagem competitiva no setor hoteleiro Ivonaldo Brandani Gusmão, Valdir Michels, Carlos Alberto Kühl

a maioria pratica a gestão hoteleira com bases científicas.

Tabela 5 - Grau de instrução do respondente

\begin{tabular}{lcc} 
& & \multicolumn{2}{c}{ Número de respondentes } \\
\cline { 2 - 4 } Grau de Instrução & $\mathbf{n}$ & $\%$ \\
\hline Ensino Médio & 3 & 7,69 \\
Curso Superior Incompleto & 1 & 2,56 \\
Curso Superior Completo & 12 & 30,77 \\
Especialização & 23 & 58,97 \\
\hline Total & $\mathbf{3 9}$ & $\mathbf{1 0 0}$ \\
\hline
\end{tabular}

\subsection{Posicionamento Estratégico}

Para competir no mercado de hotelaria e, principalmente, fortalecer o seu posicionamento estratégico, os hotéis podem optar por oferecer seus produtos ou serviços por baixo custo (menores preços do mercado), por diferenciação (melhor serviço) ou por focalização (atendimento personalizado).

No que diz respeito ao posicionamento estratégico competitivo orientado às atividades fins do hotel, a Tabela 6 mostra os seguintes resultados, segundo os gestores respondentes da pesquisa:

a) Para o setor de hospedagem dos hotéis: $61,54 \%$ estão voltados para baixo custo, oferecendo serviços com menores preços de mercado; 48,72\% utilizam estratégia de focalização, buscando atendimento personalizado, e 30,77\% se valem da estratégia de diferenciação, buscando oferecer melhor serviço;

b) Para o setor de alimentos e bebidas dos hotéis: $38,46 \%$ buscam a ênfase no baixo custo; $35,90 \%$ a estratégia de diferenciação e 25,64\% dão ênfase à focalização;

c) Para o setor de eventos: observa-se um equilíbrio entre a diferenciação e a focalização, ambos representando $25,64 \%$. Não houve respostas quanto ao item baixo custo para atender a esse quesito; e

d) Para o setor de lazer: 7,69\% buscam oferecer esse serviço com diferenciação 
As informações de custos no suporte às atividades de marketing de serviços: Uma vantagem competitiva no setor hoteleiro Ivonaldo Brandani Gusmão, Valdir Michels, Carlos Alberto Kühl

aos seus hospedes.

Conclui-se que os hotéis investigados, em geral, definem seu posicionamento estratégico adotando a estratégia de baixo custo e diferenciação, combinada com a focalização.

Tabela 6 - Posicionamento estratégico orientado as atividades do hotel (\%)

\begin{tabular}{l|c|c|c|c|c|c}
\hline & \multicolumn{2}{|c|}{$\begin{array}{c}\text { Baixo custo (BC) } \\
\text { (menores preços do mercado) }\end{array}$} & \multicolumn{2}{c|}{$\begin{array}{c}\text { Diferenciação (Di) } \\
\text { (melhor serviço) }\end{array}$} & \multicolumn{2}{c}{$\begin{array}{c}\text { Focalização (Foc) } \\
\text { (atendimento personalizado) }\end{array}$} \\
\cline { 2 - 7 } Atividades fins do hotel & Qtde & $\%$ & Qtde & $\%$ & Qtde & $\%$ \\
\hline Hospedagem & 24 & 61,54 & 12 & 30,77 & 19 & 48,72 \\
Alimentos e bebidas & 15 & 38,46 & 14 & 35,90 & 10 & 25,64 \\
Eventos & 0 & - & 10 & 25,64 & 10 & 25,64 \\
Lazer & 0 & - & 3 & 7,69 & 0 & - \\
\hline \hline \multicolumn{1}{c}{ Total } & 39 & 100 & 39 & 100 & 39 & 100 \\
\hline
\end{tabular}

A Tabela 7 mostra as atividades de apoio que sustentam a estratégia do hotel, segmentadas em cinco setores para a análise dos dados.

No setor de reservas, constata-se a utilização das três estratégias genéricas, apresentando, respectivamente, frequências de 28,21\% para o baixo custo, 17,95\% para a diferenciação e 33,33\% para a focalização.

No setor de recepção, onde se inicia o atendimento ao hóspede, 38,46\% dos respondentes afirmaram que adotam a estratégia de focalização, ou seja, procuram sempre prestar um melhor serviço ao cliente de forma personalizada, uma vez que o tratamento é fator importante na captação do mesmo, 30,77\% utilizam como estratégia o baixo custo e $35,90 \%$ na diferenciação de serviços.

No setor de governança, a estratégia de diferenciação mostra o maior nível de frequência com 28,21\%, o que traduz a preocupação dos hotéis em aprimorar, cada vez mais, a qualidade dos serviços vinculados diretamente ao setor de hospedagem. Os que adotam a estratégia de baixo custo e focalização correspondem a 23,08\% e $21,51 \%$, respectivamente, não existindo, portanto, diferença significativa na escolha da 
As informações de custos no suporte às atividades de marketing de serviços: Uma vantagem competitiva no setor hoteleiro Ivonaldo Brandani Gusmão, Valdir Michels, Carlos Alberto Kühl

estratégia pelos hotéis.

No setor de lavanderia, 17,95\% adotam o baixo custo, 15,38\% a diferenciação e $2,56 \%$ a focalização.

No setor de comunicação, os gestores responderam que adotam alguma estratégia neste setor. As frequências das estratégias adotadas nesta área revelam que os hotéis não utilizam os três tipos de estratégia genérica, apesar da maior concentração na estratégia de focalização. Respondentes representando 2,56\% afirmaram que adotam a diferenciação e 5,13\% a focalização.

Tabela 7 - Atividades de apoio que sustentam a estratégia do hotel (\%)

\begin{tabular}{l|c|c|c|c|c|c}
\hline & \multicolumn{2}{|c|}{$\begin{array}{c}\text { Baixo custo (BC) } \\
\text { Atividades fins do hotel }\end{array}$} & \multicolumn{2}{c|}{$\begin{array}{c}\text { Diferenciação (Di) } \\
\text { (melhor serviço) }\end{array}$} & \multicolumn{2}{c}{$\begin{array}{c}\text { Focalização (Foc) } \\
\text { (atendimento personalizado) }\end{array}$} \\
\cline { 2 - 7 } & Qtde & $\%$ & Qtde & $\%$ & Qtde & $\%$ \\
\hline Reservas & 11 & 28,21 & 7 & 17,95 & 13 & 33,33 \\
Recepção & 12 & 30,77 & 14 & 35,90 & 15 & 38,46 \\
Governança & 9 & 23,08 & 11 & 28,21 & 8 & 20,51 \\
Lavanderia & 7 & 17,95 & 6 & 15,38 & 1 & 2,56 \\
Comunicação & 0 & - & 1 & 2,56 & 2 & 5,13 \\
\hline \hline \multicolumn{1}{c}{ Total } & 39 & 100 & 39 & 100 & 39 & 100 \\
\hline
\end{tabular}

\subsection{Uso da Informação de Custos para fins Estratégicos}

$\mathrm{Na}$ Tabela 8 são apresentados os dados do posicionamento estratégico orientado às atividades no setor hoteleiro, segmentando os dados descritos nas Tabelas 6 e 7, por porte dos hotéis, de acordo com a classificação descrita na Tabela 2.

Tabela 8 - Uso da informação de custos para fins estratégicos nas atividades de hotelaria (\%)

\begin{tabular}{l|c|c|c|c|c|c|c|c|c|c}
\hline \multirow{2}{*}{ Informações da Contabilidade } & \multicolumn{2}{|c|}{ Muito satisfeito } & \multicolumn{2}{|c|}{ Satisfeito } & \multicolumn{2}{c|}{ Indiferente } & \multicolumn{2}{c|}{ Insatisfeito } & \multicolumn{2}{c}{ Total } \\
\cline { 2 - 11 } & Qtde & $\%$ & Qtde & $\%$ & Qtde & $\%$ & Qtde & $\%$ & Qtde & $\%$ \\
\hline \hline Custo de Fornecedores & 1 & 2,56 & 36 & 92,31 & 2 & 5,13 & 0 & 0,00 & 39 & 100 \\
Custo de Governança & 2 & 5,13 & 31 & 79,49 & 2 & 5,13 & 4 & 10,26 & 39 & 100 \\
Custo de Alimentos e Bebidas & 1 & 2,56 & 37 & 94,87 & 1 & 2,56 & 0 & 0,00 & 39 & 100 \\
Custos Operacionais & 0 & 0,00 & 35 & 89,74 & 1 & 2,56 & 3 & 7,69 & 39 & 100 \\
Custos de satisfazer clientes & 3 & 7,69 & 26 & 66,67 & 4 & 10,26 & 6 & 15,38 & 39 & 100 \\
\hline
\end{tabular}


As informações de custos no suporte às atividades de marketing de serviços: Uma vantagem competitiva no setor hoteleiro Ivonaldo Brandani Gusmão, Valdir Michels, Carlos Alberto Kühl

Os dados da tabela revelam um alto grau de satisfação, no que tange ao uso da informação de custos para fins estratégicos por parte dos gestores das empresas hoteleiras participantes do estudo.

\subsection{Fluxo de Informações sobre Marketing}

Nesta parte descreve-se a importância do fluxo de informações sobre os custos de marketing no setor de hotelaria representado na amostra. Como destacado no referencial teórico, o marketing no setor de hotelaria é um processo de planejamento e execução desde a concepção, apreçamento, promoção e distribuição de ideias, mercadorias e serviços, para criar trocas que satisfaçam os objetivos individuais e organizacionais dentro de um hotel.

A análise dos dados da Tabela 9 indica, quanto à política de mercado da empresa, que $30,77 \%$ dos hotéis de porte intermediário visam à qualidade dos produtos independente do preço, seguido pelos de médio porte com a mesma percentagem. Para os de pequeno e grande porte, apenas 23,08\% e 15,38\%, respectivamente, visam esse aspecto.

Questionados se trabalham com produtos ou preços populares, 43,75\% dos pequenos, $37,5 \%$ dos intermediários, $12,5 \%$ dos grandes e $6,25 \%$ dos médios, responderam afirmativamente.

No que se refere ao fato de trabalhar com produtos de diferentes qualidades e preços para clientes de classe socioeconômica variada, 50\% dos intermediários, 40\% para os grandes e 10\% para os hotéis de pequeno porte, afirmaram que sim.

Quanto aos procedimentos na formação de preços de seus produtos e serviços, os gestores responderam que adicionam um percentual que consideram como uma boa margem de rentabilidade para os seus produtos. Esse percentual é maior nos hotéis de porte intermediário, médio e pequeno (28,57\%) e de $14,29 \%$ nos de grande porte.

Em relação a adição de um percentual correspondente aos custos operacionais 
As informações de custos no suporte às atividades de marketing de serviços: Uma vantagem competitiva no setor hoteleiro Ivonaldo Brandani Gusmão, Valdir Michels, Carlos Alberto Kühl

mais o lucro desejado, $34,38 \%$ dos gestores de hotéis médios, $28,13 \%$ dos intermediários, $25 \%$ dos pequenos e $12,50 \%$ dos hotéis de grande porte, respoderam afirmativamente. Na Tabela 9 são apresentados os dados referentes ao entendimento dos respondentes sobre a necessidade das informações de marketing no suporte às atividades do hotel.

Tabela 9 - Fluxo das informações sobre marketing no hotel por porte (\%)

\begin{tabular}{|c|c|c|c|c|c|c|c|c|c|c|}
\hline & Qtde & $\%$ & Qtde & $\%$ & Qtde & $\%$ & Qtde & $\%$ & Qtde & $\%$ \\
\hline \multicolumn{11}{|l|}{ Visa qualidade dos produtos independente do } \\
\hline Trabalha com produtos/preços populares & 2 & 12,50 & 6 & 37,50 & 1 & 6,25 & 7 & 43,75 & 16 & 100 \\
\hline \multicolumn{11}{|l|}{$\begin{array}{l}\text { Trabalha com produtos de diferentes } \\
\text { qualidades e preços (clientes de classes }\end{array}$} \\
\hline socioeconômica variadas) & 4 & 40,00 & 5 & 50,00 & 0 & 0,00 & 1 & 10,00 & 10 & 100 \\
\hline & Qtde & $\%$ & Qtde & $\%$ & Qtde & $\%$ & Qtde & $\%$ & Qtde & $\%$ \\
\hline \multicolumn{11}{|l|}{$\begin{array}{l}\text { Adiciona um percentual que você considera } \\
\text { como uma boa margem de rentabilidade para }\end{array}$} \\
\hline seus produtos & 1 & 14,29 & 2 & 28,57 & 2 & 28,57 & 2 & 28,57 & 7 & 100,0 \\
\hline \multicolumn{9}{|l|}{ Adiciona um percentual correspondente aos } & 32 & 100,0 \\
\hline \multicolumn{11}{|l|}{$\begin{array}{l}\text { Faz uso de política diferenciada para cada } \\
\text { produto, variando o percentual de lucro/ preço }\end{array}$} \\
\hline & Qtde & $\%$ & Qtde & $\%$ & Qtde & $\%$ & Qtde & $\%$ & Qtde & $\%$ \\
\hline Vende pelo preço que pagou ao fornecedor & 1 & 12,50 & 2 & 25,00 & 2 & 25,00 & 3 & 37,50 & 8,00 & 100,0 \\
\hline $\begin{array}{l}\text { Retira sua margem de lucro que adicionou } \\
\text { anteriormente ao preço de venda } \\
\text { Recalcula seu preço de venda para a promoção } \\
\text { eliminando alguns custos fixos }\end{array}$ & 2 & 10,00 & 6 & 30,00 & 7 & 35,00 & 5 & 25,00 & 20,00 & 100,0 \\
\hline
\end{tabular}

Não houve respostas para o questionamento sobre o uso de políticas diferenciadas para cada produto, variando o percentual de lucro/preço de cada mercadoria, o que indica que os gestores dos hotéis não trabalham com margens de lucro diferenciadas por setor de atividades ou de áreas.

No que se refere aos procedimentos na determinação de preços de vendas nas promoções, os gestores responderam: 
As informações de custos no suporte às atividades de marketing de serviços: Uma vantagem competitiva no setor hoteleiro Ivonaldo Brandani Gusmão, Valdir Michels, Carlos Alberto Kühl

a) Venda ao mesmo preço que pagou ao fornecedor: responderam que sim, $37,50 \%$ dos hotéis de pequeno porte, seguidos de $25 \%$ dos intermediários e médios e $12,50 \%$ dos de grande porte.

b) Retirada da margem de lucro adicionada anteriormente ao preço de venda: responderam que sim, 35\% dos médios, 30\% dos intermediários, $15 \%$ dos pequenos e $10 \%$ dos hotéis de grande porte.

c) Recalcula seu preço de venda para a promoção eliminando alguns custos fixos: responderam que sim, 36,36\% dos médios e pequenos, seguidos de 18,18\% dos intermediários e 9,09\% dos hotéis de grande porte.

Quando os respondentes foram questionados se o hotel possui política de investimento em comunicação, 43,59\% afirmaram que sim, e 56,41\% que não. Indagados se há mensuração dos resultados obtidos com promoções, $20,51 \%$ responderam que não e 79,49\% responderam que sim.

As respostas obtidas revelam que a grande maioria dos gestores está preocupada em dispor de informações relacionadas ao custo efetivo dos serviços prestados aos hóspedes.

\section{CONCLUSÃO}

O marketing apresenta-se hoje como uma disciplina fundamental para a empresa moderna no varejo de serviços prestados diariamente a inúmeros clientes, e as empresas são obrigadas a repensar continuamente sua forma de atuação. Pensar em marketing de serviços é pensar em valor através do desempenho, e a empresa de serviços deve buscar sua diferenciação ao planejar estrategicamente seus produtos e serviços de forma a estabelecer condições que criem barreiras competitivas duráveis. Portanto, o marketing de serviços não deve ser confundido com propaganda ou 
As informações de custos no suporte às atividades de marketing de serviços: Uma vantagem competitiva no setor hoteleiro Ivonaldo Brandani Gusmão, Valdir Michels, Carlos Alberto Kühl

simplesmente vendas, mas deve lidar com os problemas de uma organização que produz serviços que satisfazem as necessidades de um determinado grupo de pessoas.

Quanto às questões levantadas no início deste artigo, questionando se os gestores dos hotéis utilizam informações de custo para desenvolver e implementar estratégias gerenciais, e se os sistemas de contabilidade de custos e gerencial desenvolvidos nos hotéis estão conseguindo fornecer informações contábeis gerenciais necessitadas pelos gestores para administrarem suas empresas e competirem no mundo atual dos negócios, verificou-se que no que diz respeito ao posicionamento estratégico dos hotéis de médio e grande porte, predomina a estratégia de diferenciação para as atividades fins como um todo. Quanto ao provimento de informações de custos estratégicos, os dados revelaram que os gestores hoteleiros pesquisados recebem mais informações de custos operacionais do que informações de custos relativas aos elos da cadeia de valor e ao mercado, focos de uma gestão estratégica.

Em relação à percepção dos gestores sobre a utilidade das informações sobre custos operacionais de fornecedores e de clientes para fins estratégicos esta foi significativa, e os gestores hoteleiros investigados responderam que custos de fornecedores são necessários para facilitar negociações e obter economias eventuais. A respeito de custos operacionais, afirmaram que são úteis para a formação de preços e para promoções, e sobre custos de clientes, acharam-nos indispensáveis para promoções e formação de preços.

Com relação às atividades de apoio, observou-se que não existe uma tendência significativa, apenas na recepção e comunicação há uma discreta ênfase para a diferenciação por serem áreas de contato com o cliente. Referindo-se à análise da cadeia de valor, a pesquisa revelou que informações estratégicas, como custos de satisfazer clientes e custos de fornecedores, não são levantadas pelos gestores.

Mais do que uma aplicação tática do marketing em serviços, este exige uma 
As informações de custos no suporte às atividades de marketing de serviços: Uma vantagem competitiva no setor hoteleiro Ivonaldo Brandani Gusmão, Valdir Michels, Carlos Alberto Kühl

estratégia de gestão. Um serviço, no final das contas, como compra de uma promessa, será julgado por aquilo que for capaz de entregar. O desafio aqui lançado, portanto, é o de unir a operação e a gestão do serviço, ao marketing. Somente assim uma empresa será capaz de prometer e entregar um serviço de alta confiabilidade ao mercado. Mais do que uma questão técnica, o marketing de serviços é um desafio de implementação.

\section{REFERÊNCIAS}

American Marketing Association. Disponível em: www.marketingpower.com. Acesso em: 16/08/2007. ANSOFF, H. I. 1977. Estratégia Empresarial. São Paulo: McGrawHill.

1991. A Nova Estratégia Empresarial. Tradução: Antônio Sanvicente Zoratto. São Paulo: Atlas.

ATKINSON, A.A.; BANKER, R.D.; KAPLAN, R.S. e YOUNG, S.M. 2000. Contabilidade Gerencial.

Tradução de André Olímpio Mosselman Du Chenoy Castro. Revisão técnica de Rubens Famá. São Paulo: Atlas, 818 p.

BRASIL. Ministério do Turismo. EMBRATUR. Boletim de desempenho do Turismo 2007. Ano IV. no 13. Disponível em http://200.189.169.141/site/br/dados_fatos/ conteudo/boletim.php?in_secao=291. Acesso em:20/03/2008.

CHANDLER, A. 1962. Strategy and Structure. MIT Press, Cambridge, MA, 432 p. COBRA, M. 2001. Marketing de turismo. 1. ed. São Paulo: Cobra Editora, 255 p.

GARRISON, R.H. e NOREEN, E.W. 2001. Contabilidade Gerencial. $9^{\circ}$ ed. Rio de Janeiro: LTC, $798 \mathrm{p}$.

HANSEN, D.R.; Moven. 2001. Gestão de Custos: contabilidade e controle. Tradução: Robert Brian Taylor. São Paulo: Pioneira, 783 p.

JOHNSON, H.T. e KAPLAN, R.S. 1996. Contabilidade Gerencial: A restauração da relevância da contabilidade nas empresas. Tradução: Ivo Korytowski. $2^{\circ}$ ed. Rio de Janeiro: Campus, 812 p.

KIM, B.Y.; OH, H. 2004. How do hotel firms obtain a competitive advantage? 
As informações de custos no suporte às atividades de marketing de serviços: Uma vantagem competitiva no setor hoteleiro Ivonaldo Brandani Gusmão, Valdir Michels, Carlos Alberto Kühl

International Journal of Contemporany Hospitality Management, 16(1):65-71.

KOTLER, P. 1998. Administração de marketing: análise, planejamento, implementação e controle. $5^{\circ}$ ed. São Paulo: Atlas, 764 p.

LEVITT, T. 1990. A imaginação de marketing. $2^{\circ}$. ed. São Paulo: Atlas, 264 p.

MAHER, M. 2001. Contabilidade de Custos: criando valor para a administração. Tradução: José Evaristo Santos. São Paulo: Atlas.

MARTINS, E. 2001. Contabilidade de Custos. 9a ed. São Paulo: Atlas, 378 p.

PORTER, M.E. 1989. Vantagem Competitiva: criando e sustentando um desempenho superior. Tradução: Elizabeth Maria de Pinho Braga. Rio de Janeiro: Campus, $897 \mathrm{p}$.

1991. Estratégia Competitiva: Técnicas para análise da indústria e da concorrência. $7^{\circ} \mathrm{ed}$. Rio de Janeiro: Campus, $448 \mathrm{p}$.

PRAHALAD, C.K. e RAMASWAMY, V. 2002. Criação de Valor: as empresas passaram o século $X X$ gerenciando eficiências. No século $X X I$, elas devem gerenciar experiências. HSM Management, 34, Set-Out, 37 p.

SHANK, J.K. e GOVINDARAJAN, V. 1997. A Revolução dos Custos: como reinventar e redefinir sua estratégia de custos para vencer em mercados crescentemente competitivos. Tradução: Luiz Orlando Coutinho Lemos. $2^{\circ}$ ed. Rio de Janeiro: Campus, $347 \mathrm{p}$.

VERGARA, S.C. 2000. Projetos e Relatórios de Pesquisa em Administração. $3^{\circ}$ ed. São Paulo: Atlas, 102 p.

Data de Submissão:19/11/2008

Data de Aceite:16/12/2008 